\title{
The effect of pregnancy and delivery on anal function in black Africans and Indians
}

\author{
TD Naidoo, ${ }^{1} \mathrm{~J}^{\mathrm{Moodley}}{ }^{2}$ \\ ${ }^{1}$ Consultant, Department of Obstetrics and Gynaecology, Greys Hospital, Pietermaritzburg and Nelson R Mandela School of \\ Medicine, University of KwaZulu-Natal \\ ${ }^{2}$ Emeritus Professor Department Obstetrics and Gynaecology and Women's Health and HIV Research Group, Nelson $R$ \\ Mandela School of Medicine, University of KwaZulu-Natal
}

Corresponding author: Dr TD Naidoo (Thinagrin.Naidoo@kznhealth.gov.za)

\begin{abstract}
Background: Occult anal sphincter disruption, following childbirth may contribute to the development of anal incontinence (AI). The type and mechanism of injury may differ between first and subsequent deliveries.

Objectives: To describe the effect of pregnancy and delivery on the endosonographic morphology of the anal sphincter and on anal sphincter pressures, and to highlight any differences in these between nulliparous and multiparous Black African and Indian women.

Methods: One hundred Black African and Indian women delivering at two hospitals in the Pietermaritzburg area underwent anal endosonography and manometry in the third trimester of pregnancy and 24 hours post-delivery. Those with occult injury were followed up at 6 weeks and six months. Participants were asked about bowel symptoms at each visit. Ante-natal and intra-partum obstetric data was also recorded.

Results: The majority were Black African ( $82 \%$ ), and $76 \%$ were multiparous. Symptoms of urgency increased from $9 \%$ antenatally to $14.6 \%$ post-delivery, decreasing to $8.3 \%$ at six months.

Symptoms of AI increased from $10 \%$ antenatally to $12.5 \%$ post-delivery, falling to $3.1 \%$ at six months. Internal sphincter defects were more common among primiparous and multiparous women delivering vaginally. There was a significant drop in functional anal length post-delivery, irrespective of the mode of delivery. Anal pressures also fell post-delivery and at six weeks post-partum. However, by six months there appeared to be a return to pregnancy values.

Conclusion: Occult anal sphincter injuries and reduced anal pressures occur after delivery, in the absence of clinically detected anal sphincter trauma, irrespective of the mode of delivery.
\end{abstract}

S Afr J Surg 2018;56(2)

http://dx.doi.org/10.17159/2078-5151/2018/v56n2a2548

\section{Introduction}

Most studies highlighting prevalence rates and predictors for the development of anal incontinence (AI) in women do so in the context of labour, childbirth and anal sphincter injury, with prevalence rates in both primipara and multipara varying from $13 \%$ to $44 \%$ between 6 weeks and 10 months post-partum..$^{1-4} \mathrm{AI}$ also occurs in pregnancy, with prevalence rates varying from 3 to $29 \%,{ }^{5-7}$ with many of the problems associated with post-partum AI being attributed to changes in ano-rectal function during pregnancy. ${ }^{6}$

Clinically detectable anal sphincter injuries occur in about $0.4-19 \%$ of vaginal deliveries. ${ }^{1,2,8}$ Ultrasound detected sphincter defects following delivery, without clinically recognised sphincter tears, occur in about 7 to $41 \%$ of cases. ${ }^{1,29-11}$ The prevalence of these occult anal sphincter injuries (OASI) vary between first and subsequent deliveries, and the mechanism of injuries differs. ${ }^{2,8}$ Some women with sphincter injury are continent, while others with intact sphincters are incontinent, suggesting factors other than injury play a role in the pathogenesis of AI. ${ }^{10}$

The results of studies exploring the impact of vaginal delivery on anal canal anatomy in the absence of sphincter disruption are conflicting. ${ }^{12,13}$ and the evidence regarding the possible association between sphincter disruption and abnormal anal pressures is also conflicting. ${ }^{8,11}$

The aims of this study were to prospectively describe the effect of pregnancy and delivery in women without clinical signs of anal sphincter tears, on endosonographic morphology of the anal sphincter and on anal sphincter pressures, and to highlight any differences in these findings between nulliparous and multiparous, Black African and Indian women. 


\section{Materials and Methods}

\section{Study design}

During a 3-month period 100 primigravidae and multigravidae volunteers agreed to participate in the study. The selection of patients was random, and the racial demographics of the study cohort were based on that of the KZN population.

The participants underwent anal endosonography and anal manometry in the third trimester of pregnancy, and 24 hours following delivery.

Data on symptoms of AI and past and current obstetric history was also collected and was unknown to the examiner until completion of the examination. Those women who sustained a sphincter tear during vaginal delivery were excluded from the study. Those who had evidence of occult injury post-delivery were followed up at 6 weeks and at six months post-partum (if the injury persisted).

The study was carried out at a district and tertiary hospital in the Pietermaritzburg Metropolitan area. The patient profile of both hospitals was considered as being similar to the KwaZulu-Natal population profile in terms of racial, socioeconomic and demographic characteristics.

Both study sites were visited by the main author (TDN) on a daily basis (Monday to Friday) during the initial 3-month recruitment period.

\section{Inclusion and exclusion criteria}

The inclusion criteria were all pregnant women of either Black African or Indian descent who intended delivering vaginally. Women with a history of anal surgery, anorectal dysfunction, or any medical condition and or obstetric condition that might preclude vaginal delivery were not eligible.

\section{Data collection}

Antenatal and intrapartum obstetric data were obtained from the patients' records. Data recorded in the antenatal period included age, weight, height, race, social status and parity. Data on past obstetric delivery history (normal vaginal delivery or not) was collected; RPR for syphilis and Elisa for HIV status were recorded antenataly.

Obstetric data was collected on the mode of delivery, duration of labour, induction and augmentation of labour, epidural use, instrumental delivery, episiotomy use, perineal tears and birth weight of the baby. All variables were precategorised in the questionnaire. At each time period, all women completed a structured symptom questionnaire about fecal urgency and AI. Fecal urgency was defined as the inability to defer defecation for more than five minutes. AI included either incontinence of flatus, liquid stool, or solid stool or both.

\section{Anal endosonography}

Anal endosonographic examinations were performed with the patient in the left lateral position using the InNovaSound $\mathrm{USB}^{\circledR}$ endocavity ultrasound probe. This is a $360^{\circ}$ rotating $7.5 \mathrm{MHz}$ endoprobe. The probe was gently inserted until the puborectalis muscle was identified and then withdrawn down the anal canal; images of the puborectalis, external anal sphincter (EAS), and internal anal sphincter (IAS) were captured. A defect in the sphincter was defined as a break in the hypo echogenic ring of the IAS or the hyper echogenic ring of the EAS.

\section{Anal manometry}

Anal manometry was performed with the modified Stryker intra-compartmental pressure monitor (Stryker, Kalamazoo, Michigan) attached to an air-filled micro balloon, as first described by Orrom et al. (1990). ${ }^{14}$ Maximum resting anal pressure (MRP), maximum squeeze pressure (MSP) and anal canal length were measured at $1 \mathrm{~cm}$ intervals along the anal canal from the anal verge with the use of a station pullthrough technique. The principal investigator carried out all anal manometry and Endoanal ultrasound examinations.

\section{Data analysis}

Data was captured in Microsoft Excel and analysed in SPSS version 21 (SPSS Inc., Chicago, Illinois, USA). Frequencies and means with standard deviations were used to describe the categorical and continuous variables respectively. The dependent variables being studied were flatal incontinence, liquid and solid fecal incontinence and both flatal and fecal incontinence and anal sphincter defects as identified at each time point of the study. Chi square was used to test for a significant association between race and anal sphincter defects. The independent samples t-test was used to test for significant associations between anal manometry and anal sphincter defects. The accepted level of significance was $0.05(\alpha=0.05)$.

\section{Regulatory approvals}

The Biomedical Research Ethics Committee of the University of KwaZulu-Natal approved the study protocol. The study was also approved by the KwaZulu-Natal Department of Health and institutional ethical approval was obtained from the relevant hospital CEOs.

\section{Results}

\section{Demographics and obstetric factors:}

A total of 100 women were recruited in the antenatal period with four women being lost to follow-up. The majority of the participants were Black African (82\%), and $76 \%$ were muiltiparous. Sixty-two were less than 30 years of age and 37 weighed more than 110 kilograms; $86 \%$ percent of women were considered to be of a low socio-economic status; $37 \%$ percent were HIV positive and $6 \%$ had a reactive syphilis serology (Table 1); 45\% had a normal vaginal delivery and $29 \%$ had emergency caesarean section (c/s) after labouring. An estimated $56 \%$ of women experienced less than 12 hours of labour, $15.6 \%$ had an episiotomy (all medio-lateral) and $21.9 \%$ had perineal tears; $60.4 \%$ of women delivered babies who weighed three kilograms or more (Table2). 


\begin{tabular}{|c|c|}
\hline Demographics & $\%$ \\
\hline \multicolumn{2}{|l|}{ Age (years) } \\
\hline$<20$ & 22 \\
\hline $20-29$ & 40 \\
\hline 30-39 & 28 \\
\hline $40-49$ & 10 \\
\hline \multicolumn{2}{|l|}{ Race } \\
\hline African & 82 \\
\hline Indian & 18 \\
\hline \multicolumn{2}{|l|}{ Weight (kg) } \\
\hline $40-59$ & 14 \\
\hline $60-79$ & 49 \\
\hline $110-119$ & 33 \\
\hline$\geq 120$ & 4 \\
\hline \multicolumn{2}{|l|}{ Height (cm) } \\
\hline$<1.2$ & - \\
\hline $1.2-1.39$ & 12 \\
\hline $1.4-1.69$ & 85 \\
\hline $1.7-1.89$ & - \\
\hline$>1.9$ & 3 \\
\hline \multicolumn{2}{|l|}{ Social Status } \\
\hline High & 14 \\
\hline Low & 86 \\
\hline HIV positive & 37 \\
\hline RPR positive & 6 \\
\hline \multicolumn{2}{|l|}{ Parity } \\
\hline Primiparous & 24 \\
\hline Multiparous & 76 \\
\hline
\end{tabular}

\section{Symptoms of incontinence:}

Symptoms of urgency increased from $9 \%$ in the antenatal period to $14.6 \%$ post-delivery. Thereafter decreasing to $10.3 \%$ at six weeks and $8.3 \%$ at six months post-partum. Symptoms of $\mathrm{AI}$ increased from $10 \%$ in the antenatal period to $12.5 \%$ post-delivery and continued to increase to $17.6 \%$ at six weeks post-partum. At six months post-partum, symptoms of AI were reported by $3.1 \%$ of women (Table 3 ).

\section{Occult anal sphincter defects detected by endoanal} ultrasound:

In the post-delivery, six weeks and six months period both primiparous and multiparous women who had normal

\begin{tabular}{|c|c|}
\hline Mode of delivery & $\mathbf{N}(\%)$ \\
\hline NVD & $43(44.8)$ \\
\hline Emergency $\mathrm{C} / \mathrm{S}$ & $28(29.2)$ \\
\hline Scheduled C/S & $25(26.0)$ \\
\hline \multicolumn{2}{|l|}{ Duration of Labour } \\
\hline$<6$ hours & $27(28.1)$ \\
\hline 6-12 hours & $27(28.1)$ \\
\hline$>12-24$ hours & $8(8.3)$ \\
\hline \multicolumn{2}{|l|}{ Duration of 2nd stage } \\
\hline$<1$ hour & $28(29.2)$ \\
\hline 1-2 hours & $12(12.5)$ \\
\hline$>2-3$ hours & $4(4.2)$ \\
\hline$>3$ hours & $1(1.0)$ \\
\hline Induction of Labour & $11(11.5)$ \\
\hline Augmentation & $6(6.3)$ \\
\hline Episiotomy & $15(15.6)$ \\
\hline Primiparous & 3 \\
\hline Multiparous & 12 \\
\hline Tears & $21(21.9)$ \\
\hline 1st and 2 nd degree & $15(15.6)$ \\
\hline Primiparous & 4 \\
\hline Multiparous & 11 \\
\hline 3rd and 4th degree & $6(6.3)$ \\
\hline Primiparous & 1 \\
\hline Multiparous & 5 \\
\hline Instrumentation & $9(9.4)$ \\
\hline Forceps & $4(4.2)$ \\
\hline Vacuum & $5(5.2)$ \\
\hline Epidural & $6(6.3)$ \\
\hline \multicolumn{2}{|l|}{ Birth Weight (kg) } \\
\hline $2.0-2.5$ & $11(11.5)$ \\
\hline$>2.5-3.0$ & $25(26.0)$ \\
\hline$>3.0-3.5$ & $42(43.8)$ \\
\hline$>3.5-4.0$ & $13(13.5)$ \\
\hline$>4.0$ & $3(3.1)$ \\
\hline Missing & $2(2.1)$ \\
\hline
\end{tabular}

vaginal deliveries had IAS defects more frequently than EAS defects or a combination of IAS and EAS defects. Similarly, primiparous women who had deliveries by $\mathrm{C} / \mathrm{S}$ had IAS defects at six weeks more frequently than other types of anal sphincter defects (Table 4).

Table 3: Symptoms of incontinence measured at each time point in the study

\begin{tabular}{|c|c|c|c|c|}
\hline Symptoms & $\begin{array}{c}\text { Antenatal } \\
(n=100)\end{array}$ & $\begin{array}{c}\text { Post-partum } \\
(\mathbf{n}=96) \\
\mathbf{N}(\%)\end{array}$ & $\begin{array}{c}\text { Six weeks } \\
(\mathbf{n}=96) \\
\mathbf{N}(\%)\end{array}$ & $\begin{array}{c}\text { Six months } \\
(\mathrm{n}=96) \\
\mathrm{N}(\%)\end{array}$ \\
\hline Urgency (yes) & 9 & $14(14.6)$ & $10(10.4)$ & $8(8.3)$ \\
\hline AI symptoms & 10 & $12(12.5)$ & $17(17.7)$ & $3(3.1)$ \\
\hline Flatus & 5 & $7(7.3)$ & $7(7.3)$ & $1(1.0)$ \\
\hline Liquid Faeces & 3 & $3(3.1)$ & $5(5.2)$ & $1(1.0)$ \\
\hline Solid Faeces & 1 & - & $2(2.1)$ & $1(1.0)$ \\
\hline Both Liquid \& Solid Faces & 1 & $2(2.1)$ & $3(3.1)$ & - \\
\hline
\end{tabular}


Table 4: Anal sphincter defects in women evaluated by EAUS at each time point in the study.

\begin{tabular}{|c|c|c|c|c|}
\hline \multirow{2}{*}{\multicolumn{2}{|c|}{ Mode of delivery and parity group }} & \multicolumn{3}{|c|}{ Anal sphincter defects } \\
\hline & & \multirow[t]{2}{*}{$\begin{array}{c}\text { Internal sphincter } \\
\mathbf{N}(\%) \\
\end{array}$} & \multirow[t]{2}{*}{$\begin{array}{c}\text { External sphincter } \\
\text { N (\%) } \\
\end{array}$} & \multirow[t]{2}{*}{$\begin{array}{c}\text { Internal and external } \\
\text { sphincter } \mathbf{N}(\%)\end{array}$} \\
\hline & NVD & & & \\
\hline \multirow[t]{4}{*}{ Primiparous } & Antenatal $(\mathrm{n}=15)$ & - & - & - \\
\hline & Post-delivery $(n=14)$ & $8(57.1)$ & $4(28.6)$ & $4(28.6)$ \\
\hline & Six weeks $(\mathrm{n}=8)$ & $6(75.0)$ & $2(25.0)$ & $2(25.0)$ \\
\hline & Six months $(n=7)$ & $5(71.4)$ & $1(14.3)$ & $1(14.3)$ \\
\hline \multirow[t]{4}{*}{ Multiparous } & Antenatal $(\mathrm{n}=28)$ & $3(10.7)$ & $4(14.3)$ & $2(7.1)$ \\
\hline & Post-delivery $(n=27)$ & $12(44.4)$ & $10(37.0)$ & $8(29.6)$ \\
\hline & Six weeks $(n=14)$ & $9(64.3)$ & $8(57.1)$ & $4(28.6)$ \\
\hline & Six months $(n=14)$ & $6(42.9)$ & $3(21.4)$ & $1(7.1)$ \\
\hline \multicolumn{5}{|c|}{ Caesarean section } \\
\hline \multirow[t]{4}{*}{ Primiparous } & Antenatal $(\mathrm{n}=8)$ & - & - & - \\
\hline & Post-delivery $(\mathrm{n}=8)$ & $2(25.0)$ & $2(25.0)$ & $1(12.5)$ \\
\hline & Six weeks $(n=2)$ & $2(100.0)$ & $1(50.0)$ & $1(50.0)$ \\
\hline & Six months $(n=4)$ & $2(50.0)$ & $1(25.0)$ & $1(25.0)$ \\
\hline \multirow[t]{4}{*}{ Multiparous } & Antenatal $(n=45)$ & $10(22.2)$ & $9(20.0)$ & $6(13.3)$ \\
\hline & Post-delivery $(n=45)$ & $8(17.8)$ & $8(17.8)$ & $6(13.3)$ \\
\hline & Six weeks $(n=6)$ & $4(66.7)$ & $6(100)$ & $4(66.7)$ \\
\hline & Six months $(n=12)$ & $1(8.3)$ & $1(8.3)$ & $1(8.3)$ \\
\hline
\end{tabular}

\section{Table 5: Anal sphincter defects by race at each time point in} the study

\begin{tabular}{lll}
\hline & African N(\%) & Indian N(\%) \\
\hline Antenatal $(\mathbf{n}=\mathbf{1 0 0})$ & $11(13.1)$ & $2(11.1)$ \\
IAS defect & $12(14.6)$ & $1(5.6)$ \\
EAS defect & $7(8.5)$ & $1(5.6)$ \\
IAS \& EAS defect & & \\
Post-delivery $(\mathbf{n}=\mathbf{9 4})$ & $24(31.2)$ & $6(35.5)$ \\
IAS defect & $20(26.0)$ & $4(23.5)$ \\
EAS defect & $15(19.5)$ & $4(23.5)$ \\
IAS \& EAS defect & & \\
Six weeks $(\mathbf{n}=\mathbf{3 0})$ & $15(62.5)$ & - \\
IAS defect & $14(58.3)$ & $3(50.0)$ \\
EAS defect & $8(33.3)$ & $3(50.0)$ \\
IAS \& EAS defect & & $2(18.2)$ \\
Six months $(\mathbf{n}=\mathbf{3 7})$ & $9(34.6)$ & $5(45.5)$ \\
IAS defect & $4(15.4)$ & \\
EAS defect & $2(7.7)$ & \\
IAS \& EAS defect & & \\
Chi square, $\mathbf{p}<0.05$ & & \\
& &
\end{tabular}

At all time periods of the study there was no significant association between race and OASI as measured by EAUS (Table 5).

\section{Anal manometry:}

There was a significant drop in functional anal length postdelivery, irrespective of the mode of delivery. The maximal resting anal (MRP) and squeeze pressures (MSP) also fell post-delivery and at six weeks post-partum. However, by six months there appeared to be a return to pregnancy values (Table 6).

In the antenatal period, the functional anal length (FAL) was significantly higher $(\mathrm{p}=0.042)$ and the MSP significantly lower $(p=0.038)$ in those women who had EAS defects. The MSP was also significantly lower $(p=0.014)$ antenatally in women with combined IAS and EAS defects. Post-delivery MRP significantly decreased in women with IAS defects $(p=0.044)$, and combined IAS and EAS defects $(p=0.04)$. Post-delivery MSP significantly decreased in women with IAS defects $(\mathrm{p}=0.019)$, EAS defects $(\mathrm{p}=0.004)$ and combined IAS and EAS defects $(\mathrm{p}<0.01)$. At six months FAL increased significantly $(p=0.018)$ in women who had combined IAS and EAS defects (Table 7). 


\begin{tabular}{|c|c|c|c|c|}
\hline Type of Delivery & $\begin{array}{c}\text { In pregnancy } \\
\text { Mean (SD) }\end{array}$ & $\begin{array}{c}\text { Post delivery } \\
\text { Mean (SD) }\end{array}$ & $\begin{array}{c}\text { Six weeks } \\
\text { Mean (SD) }\end{array}$ & $\begin{array}{l}\text { Six months } \\
\text { Mean (SD) }\end{array}$ \\
\hline \multicolumn{5}{|l|}{ NVD $(n=43)$} \\
\hline FAL (cm) & $6.51(0.93)$ & $6.33(0.91)$ & $5.61(0.94)$ & $4.99(0.96)$ \\
\hline MRP (mmHg) & $50.77(9.89)$ & $41.56(9.75)$ & $40.77(9.76)$ & 48.38 (10.89) \\
\hline MSP (mmHg) & $70.14(9.38)$ & $57.32(10.79)$ & $58.27(10.79)$ & $65.67(11.53)$ \\
\hline \multicolumn{5}{|l|}{$C$ section $(n=53)$} \\
\hline FAL $(\mathrm{cm})$ & $6.74(1.11)$ & $6.59(1.09)$ & $6.28(2.09)$ & $5.07(0.83)$ \\
\hline MRP (mmHg) & $50.13(12.75)$ & $48.09(11.85)$ & $42.38(20.23)$ & $49.31(9.63)$ \\
\hline MSP (mmHg) & $68.53(13.14)$ & $65.23(12.15)$ & $56.50(17.66)$ & $64.50(10.01)$ \\
\hline
\end{tabular}

Table 7: Bivariate associations between anal sphincter defects and anal manometry

\begin{tabular}{|c|c|c|c|c|c|c|}
\hline & \multicolumn{2}{|c|}{ Internal anal sphincter defect } & \multicolumn{2}{|c|}{ External anal Sphincter defect } & \multicolumn{2}{|c|}{ Combined IAS and EAS defect } \\
\hline & $\begin{array}{c}\text { Yes } \\
\text { Mean (SD) }\end{array}$ & $\begin{array}{c}\text { No } \\
\text { Mean (SD) }\end{array}$ & $\begin{array}{c}\text { Yes } \\
\text { Mean (SD) }\end{array}$ & $\begin{array}{c}\text { No } \\
\text { Mean (SD) }\end{array}$ & $\begin{array}{c}\text { Yes } \\
\text { Mean (SD) }\end{array}$ & $\begin{array}{c}\text { No } \\
\text { Mean (SD) }\end{array}$ \\
\hline \multicolumn{7}{|c|}{ Antenatal $(n=100)$} \\
\hline FAL $(\mathrm{cm})$ & $6.35(1.13)$ & $6.61(1.07)$ & $7.15(1.66)$ & $6.50(0.95)^{*}$ & $6.55(1.84)$ & $6.58(1.07)$ \\
\hline MRP (mmHg) & $51.08(14.33)$ & $50.25(11.42)$ & $48.15(14.51)$ & $50.69(11.34)$ & $48.00(14.17)$ & $50.57(11.59)$ \\
\hline MSP (mmHg) & $64.31(15.85)$ & $69.68(11.33)$ & $62.54(15.61)$ & $69.94(11.23)^{*}$ & $59.00(18.28)$ & $69.85(11.08)^{*}$ \\
\hline \multicolumn{7}{|c|}{ Post-delivery $(n=94)$} \\
\hline FAL $(\mathrm{cm})$ & $6.33(0.94)$ & $6.55(1.05)$ & $6.68(1.26)$ & $6.41(0.92)$ & $6.38(0.88)$ & $6.50(1.05)$ \\
\hline MRP (mmHg) & $41.80(11.56)$ & $46.86(11.05)^{*}$ & $42.00(11.68)$ & $46.36(11.17)$ & $40.47(10.37)$ & $46.45(11.39)^{*}$ \\
\hline MSP (mmHg) & $57.50(12.53)$ & $63.78(11.57)^{*}$ & $55.67(12.37)$ & $63.87(11.46)^{* *}$ & $53.16(2.66)$ & $63.96(1.32)^{* *}$ \\
\hline \multicolumn{7}{|c|}{ Six weeks $(n=30)$} \\
\hline FAL $(\mathrm{cm})$ & $5.65(0.98)$ & $6.12(1.97)$ & $5.95(1.67)$ & $5.58(0.69)$ & $5.73(1.19)$ & $5.83(1.44)$ \\
\hline MRP (mmHg) & $38.38(12.24)$ & $47.78(12.89)$ & $43.24(15.15)$ & $38.54(9.34)$ & $41.09(15.23)$ & 41.26 (11.93) \\
\hline MSP (mmHg) & $55.62(12.04)$ & 62.89 (12.99) & $55.71(14.47)$ & $60.54(9.39)$ & $53.64(14.84)$ & $60.21(10.74)$ \\
\hline \multicolumn{7}{|c|}{ Six months $(n=37)$} \\
\hline FAL $(\mathrm{cm})$ & $5.21(1.08)$ & $4.90(0.76)$ & $5.43(1.58)$ & $4.94(0.71)$ & $6.00(1.64)$ & $4.90(0.72)^{*}$ \\
\hline MRP (mmHg) & $46.93(12.61)$ & $49.91(8.60)$ & $49.33(16.88)$ & $48.68(8.84)$ & $58.75(15.71)$ & $47.82(9.27)$ \\
\hline MSP (mmHg) & $68.00(10.46)$ & $63.43(10.81)$ & $63.17(15.46)$ & $65.55(9.92)$ & $69.75(13.50)$ & $64.61(10.51)$ \\
\hline
\end{tabular}

\section{Discussion}

This study highlights the fact that pregnancy and delivery areassociated with the disruption of anal function.

The high antenatal prevalence of bowel symptoms suggests that pregnancy itself is a risk factor for AI, contrary to evidence which predominantly implicates labour and delivery. ${ }^{3,4} \mathrm{O}^{\text {'Boyle et al. }}{ }^{7}$ in their study in 2008 highlighted a high prevalence of AI symptoms in pregnancy; while van Brummen et al. ${ }^{6}$ showed that symptoms of AI are already present in early pregnancy and are predictive for reporting symptoms after delivery. It is possible that the hormonal changes in pregnancy and the weight of the conceptus, together with alterations in the pelvic floor, and anal and perineal anatomy play a role in the pathophysiology of AI in pregnancy.

The increase in prevalence of bowel symptoms in the postpartum period through to 6 weeks, followed by the marked decline at 6 months is in keeping with other studies which show that $13-25 \%$ of women report faecal incontinence at 3 to 6 months post-delivery, with a decline in prevalence 
over time..$^{3,4,7}$ This reduction in prevalence over time is encouraging, suggesting that post-partum AI may be transient, and in those women in whom symptoms persisted at 6 months the factors involved in the pathophysiology maybe obstetric related..$^{3,4}$

The high prevalence of perineal tears $(22 \%)$ and OASI (44\%) evident in this study suggests that labour and delivery, together with the changes occurring in pregnancy predispose women to pelvic floor trauma. In keeping with previous studies $^{8,10,11}$ none of the primigravid patients in our study had evidence of OASI in the antenatal period. Post-delivery, however, the numbers of new OASI were comparable between the primigravid and multiparous groups with only a slight increase in the multiparae, thus corroborating evidence which suggests that first delivery may pose the greatest risk for anal sphincter injury. ${ }^{8}$ Our finding that $\mathrm{C} / \mathrm{S}$ was not protective against OASI in both primigravid and multiparous patients may be due to the fact that that many of the women had laboured prior to the $\mathrm{C} / \mathrm{S}$, or as previously mentioned pregnancy alone could be a contributory factor. ${ }^{5,7}$ Bols et al. ${ }^{3}$ have also shown $\mathrm{C} / \mathrm{S}$ not to be protective against $\mathrm{AI}$.

Zetterstrom et al. ${ }^{9}$ however found no evidence of OASI on EAUS in their $\mathrm{C} / \mathrm{S}$ patients post-delivery, although $36 \%$ had incontinence of flatus. The fact that we documented OASI post-delivery in the primigravidae irrespective of the mode of delivery further supports the theory that obstetric variables, such as the duration of labour, induction and augmentation of labour, instrumentation, the use of epidural and birth weight may be a factor in the development of OASI.

Defects involving the IAS or a combination of both IAS and EAS occurred most commonly at all time points in this study. There is lack of consensus regarding which sphincter is more likely to be injured. Sultan et al. ${ }^{8}$ in 1993 found IAS defects to be most common, while Chaliha et al..$^{5}$ in 2001 and Zetterstrom et al. ${ }^{9}$ in 2003 found EAS defects to be the commonest. These conflicting findings are difficult to explain. Sultan et al. ${ }^{8}$ suggested that shearing forces produced by fetal skull descent causes isolated injury to the IAS, a mechanism that might be different to that causing injury to the EAS; while Zetterstrom et al. ${ }^{9}$ argued that this was a shortcoming of EAUS, where the IAS is well visualised but anterior defects in the EAS are more difficult to visualise. The persistence of a greater number of IAS defects at 6 weeks and 6 months suggest that this might be a more permanent form of structural damage than EAS defects. Guzman Rojas et al. ${ }^{2}$ also suggested that IAS defects may have a poorer prognosis in the long term.

Our findings of a significant reduction in MRP and MSP post-delivery as compared to pre-delivery values were similar to other studies ${ }^{5,8,11}$ further supporting the theory that labour and delivery rather than pregnancy alone predisposes women to pelvic floor trauma.

The significant association between lower MSP values and EAS defects both antenatally and post-partum, and lower MRP values and IAS defects post-partum is consistent with the findings of other studies that suggest that the EAS contributes predominantly to anal squeeze pressure and the
IAS to anal resting pressure. ${ }^{5}$ Likewise combined IAS and EAS defects were associated with a decrease in both resting and squeeze pressures, emphasising the contribution of both sphincters to overall anal canal pressures.

Injury to the pudendal nerve, connective tissue and pelvic floor supports may also lead to a reduction in MSP. ${ }^{5}$ A gradual improvement in anal pressures over time was also evident in this study, which was in keeping with the findings of Nazir et al. ${ }^{11}$

The fact that only one investigator carried out all the EAUS and manometric investigations can be regarded as a limitation of this study, as this could have introduced bias. However, the fact that the same person performed these examinations before and after delivery throughout the investigation is more likely to increase the accuracy rather than reduce it. EAUS is not an exact method, but it is relatively easy to perform and the findings were comparable with other studies.

A further limitation of our study included the small sample size of our study population, mainly due to the difficulty in recruiting volunteers given the nature of the investigations. This may explain why our study did not show any association between race and OASI which is surprising, given that interracial variation in incidences of AI and obstetric perineal injuries has been documented. ${ }^{15}$

\section{Conclusion}

This study highlights the fact that OASI and reduced anal pressures may arise after delivery, in the absence of clinically detected anal sphincter trauma, irrespective of the mode of delivery. The consequences of this may not manifest for some years until there is further deterioration of anal sphincter function, as a result of further pregnancies and deliveries, aging, menopause, or changes in collagen. Long-term followup is necessary to assess the impact of these endosonographic anal sphincter injuries on the development of incontinence in later life. However, in resource constrained settings like ours this may prove challenging. Furthermore, many of the investigations are considered intrusive, invasive and embarrassing to the affected individual leading to reluctance to comply with follow-up.

\section{REFERENCES}

1. Andrews V, Sultan A, Thakar R, Jones P. Occult anal sphincter injuries - myth or reality? BJOG. 2006;113:195-200. [http:// dx.doi.org/10.1111/j.1471-0528.2006.00799]. PMID:16411998

2. Guzman Rojas RA, Shek KL, Langer SM, Dietz HP. Prevalence of anal sphincter injury in primiparous women. Ultrasound Obstet Gynecol. 2013;42:461-6. [http://dx.doi.org/ 10.1002/ uog.12481]. PMID: 23576493.

3. Bols EMJ, Hendriks EJM, BerghmansBCM, Beaten CGMI, Nijhuis JG, Bie RA de. A systematic review of etiological factors for postpartum fecal incontinence. Acta Obstet Gynecol Scand. 2010;89(3):302-14. http://dx.doi.org/10.3109/00016340 903576004]. PMID: 20199348.

4. Zetterstrom J. Lopez A, Anzen B, Dolk A, Norman M, Mellgren A. Anal incontinence after vaginal delivery: a prospective study in primiparous women. Br J Obstet Gynaecol. 1999;106:324330. [http://dx.doi.org/10.1111/j.1471-0528.1999.tb08269]. 
PMID:10426238.

5. Chaliha C, Sultan AH, Bland JM, Monga AK, Stanton SL. Anal function: effect of pregnancy and delivery. Am J Obstet Gynecol. 2001;185:427-32. [http://dx.doi.org/10.1067/ mob.2001.115997]. PMID:11518904.

6. van Brummen HJ, Bruinse HW, van de Pol G, Heintz AP, van der Vaart CH. Defecatory symptoms during and after the first pregnancy: prevalences and associated factors. Int Urogynecol J Pelvic Floor Dysfunct. 2006;17(3);224-30. PMID: 16077997.

7. O'Boyle AL, O'Boyle JD, Magann EF, Rieg TS, Morrison JC, Davis GD. Anorectal symptoms in pregnancy and the postpartum period. J Reprod Med. 2008;53(3):151-4. PMID: 18441716

8. Sultan AH, Kamm MA, Hudson CN, Thomas JM, Bartram CI. Anal sphincter disruption during vaginal delivery. N Engl J Med. 1993;329:1905-11. [http://dx.doi.org/ 10.1056/ NEJM199312233292601]. PMID: 8247054.

9. Zetterstrom J, Lopez A, Holmstrom B, et al. Obstetric sphincter tears and anal incontinence: an observational follow-up study. Acta Obstet Gynecol Scand. 2003;82:921-8. [http://dx.doi.org/1 0.1034/j.1600-0412.2003.00260]. PMID:12956842.

10. Abramowitz L, Sobhani I, Ganansia R, et al. Anal sphincter defects the cause of anal incontinence after vaginal delivery? Results of a prospective study. Dis Colon Rectum 2000;43:5908. PMID: 10826416.
11. Nazir M, Carlsen E, Nesheim B-I. Do occult anal sphincter injuries, vector volume manometry and delivery variables have any predictive value for bowel symptoms after first time vaginal delivery without third and fourth degree rupture? A prospective study. Acta Obstet Gynecol Scand. 2002;81:7206. [http://dx.doi.org/10.1034/j.1600-0412.2002. 810806]. PMID:12174155.

12. Frudinger A, Halligan S, Bartram CI, Spencer JA, Kamm MA. Changes in anal anatomy following vaginal delivery revealed by anal endosonography. Br J Obstet Gynaecol. 1999;106:2337. PMID:10426642.

13. Williams $\mathrm{AB}$, Bartram $\mathrm{CI}$, Halligan $\mathrm{S}$, et al. Alteration of anal sphincter morphology following vaginal delivery revealed by multiplanar anal endosonography. Br J Obstet Gynaecol. 2002;109:942-6. [http://dx.doi.org/10.1111 /j.1471-0528.2002.00251]. PMID:12197376.

14. Orrom WJ, Williams JG, Rothenberger DA, Wong WD. Portable anorectal manometry. Br J Surg. 1990;77:876-7. PMID:2393808.

15. Naidoo TD, Moodley J, Esterhuizen TE. Incidence of postpartum anal incontinence among Indians and black Africans in a resource-constrained country. Int $\mathrm{J}$ Gynecol Obstet. 2012;118:156-60. [http://dx.doi.org/10.1016/j. ijgo.2012.03.027]. PMID:22624871. 